\title{
Materials recovery from waste printed circuit boards by supercritical methanol
}

\author{
Fu-Rong Xiu, Fu-Shen Zhang* \\ Research Center for Eco-Environmental Sciences, Chinese Academy of Sciences, 18 Shuangqing Road, Beijing 100085, China
}

\section{A R T I C L E I N F O}

\section{Article history:}

Received 5 November 2009

Received in revised form 22 January 2010

Accepted 25 January 2010

Available online 2 February 2010

\section{Keywords:}

Waste PCBs

Recovery

Supercritical methanol

Polymer

WEEE

\begin{abstract}
A B S T R A C T
The recovery of valuable materials from waste printed circuit boards (PCBs) is quite difficult due to the heterogeneous mix of polymer materials, multiple kinds of metals and glass fiber. A feasibility study was conducted using supercritical methanol (SCM) to simultaneously recover polymers and metals from waste PCBs. The study focused on the characteristics of both oils and solid products obtained from the SCMtreated waste PCBs. The operation conditions were temperature range of $300-420^{\circ} \mathrm{C}$, treatment time between 30 and 120 min and solid-to-liquid ratio (S/L) of 1:10-1:30 (g/mL) so as to understand the products and depolymerization mechanisms of waste PCBs in SCM. GC-MS results revealed that the oils mainly contained phenol and its methylated derivatives, and the methylated derivatives increased with the increase of reaction temperature. The methylated reaction occurred mainly above $400{ }^{\circ} \mathrm{C}$. The liquid products also contained a significant number of phosphated fire retardant additives such as triphenyl phosphate, which decreased significantly with the increase of reaction temperature. The solid product mainly consisted of $\mathrm{Cu}, \mathrm{Fe}, \mathrm{Sn}, \mathrm{Pb}$ and $\mathrm{Zn}$, as well as lower concentrations of precious metals such as $\mathrm{Ag}$ and $\mathrm{Au}$.

(c) 2010 Elsevier B.V. All rights reserved.
\end{abstract}

\section{Introduction}

With rapid growth of the electronic industry and worldwide environmental awareness, the treatment of waste electrical and electronic equipment (WEEE) is of great importance for sustainable development. WEEE is a complex material containing various recyclable fractions while printed circuit boards (PCBs) are the primary element in most WEEE [1]. Waste PCBs were a mixture with many metals such as $\mathrm{Cu}, \mathrm{Fe}, \mathrm{Pb}, \mathrm{Zn}$, mixed with large number of polymers and ceramics [2]. The polymers in waste PCBs are thermoplastic and thermosetting resins, which are intermingled very much and also have metals or other materials embedded inside [3]. Therefore the separation and recycling of the individual components of the polymers in waste PCBs are very difficult [4].

Currently, three types of recycling ways for the polymers in waste PCBs are considered, i.e. material recycling, thermal recycling, and chemical recycling, among which chemical recycling is believed to be the promising process $[5,6]$. Chemical recycling is to decompose the waste polymers into their monomers or some useful chemicals by means of chemical reactions. Pyrolysis is a chemical recycling technique that has been widely researched [7-10] as a method of recycling polymers in waste PCBs. During the pyrolysis process (heating without oxygen), the organic part is decomposed to low molecular products (liquids or gases), which can be used as fuel or chemical source.

\footnotetext{
* Corresponding author. Tel.: +86 10 62849515; fax: +861062849515

E-mail address: fszhang@rcees.ac.cn (F.-S. Zhang).
}

In recent years, supercritical fluid is focused as an effective medium for the conversion of waste materials into resources [11-16]. Supercritical fluid is the substance whose temperature and pressure are over its critical points. Supercritical water (SCW) has been successfully applied to the process of decomposition of stable organic wastes [17-20]. In our previous study $[17,18]$, SCW process was developed for the treatment of toxic organic matters in waste PCBs. SCW also has been applied to chemical recovery of polymers by many researchers $[19,20]$. Tagaya et al. have studied the decomposition reactions of epoxy resin in SCW [20]. Goto et al. reported that the depolymerization of PCBs in suband supercritical water [19].

However, the critical temperature and pressure of water $\left(T_{\mathrm{C}}=374^{\circ} \mathrm{C}, P_{\mathrm{C}}=22.1 \mathrm{MPa}\right)$ are very high which result in the very serious corrosion of reactor and the higher energy consumption, and require equipment which makes commercial usage of SCW expensive [21,22]. Possible merits of utilizing supercritical methanol (SCM) over SCW are found in the following respects [22]. First, the operation condition will be milder because the critical temperature and pressure of methanol $\left(T_{\mathrm{c}}=240^{\circ} \mathrm{C}, P_{\mathrm{c}}=8.09 \mathrm{MPa}\right)$ are lower than those of water. This would widen the selection of materials for the reactors. Second, the separation of products from the solvent is much easier than the case using SCW, because the boiling point of methanol is lower than that of water. Third, alteration or modification of the product distribution would also be expected by changing the solvent. Additionally, solvent methanol also can be recycled during the recovery process. Some researchers $[21,23]$ reported the application of SCM for chemical recovery of molding resins such as cross-linked polyethylene and phenol resin. 
To the best of our knowledge, thus far, there is no report about the treatment of waste PCBs in SCM for materials recovery.

In this study, we attempted to develop a highly efficient and benign process for materials recovery from waste PCBs in SCM. The objectives of the study are (1) to make clear how the reaction conditions such as temperature, time and solid-to-liquid ratio $(\mathrm{S} / \mathrm{L})$ influenced the conversion of polymer in waste PCBs and (2) to study what kinds of species are included in the liquid product which is expected to obtain, and the metals composition of solid product obtained from the SCM-treated waste PCBs.

\section{Materials and methods}

\subsection{Materials}

Waste PCBs used in this work were supplied by HUAXING Environmental Protection Company of Beijing. The waste PCBs were mainly disassembled from discarded telephones, PCs, and other electrical equipment. After the components (relays, capacitors, etc.) were disassembled, the PCBs were sent to comminute in a cutting mill until the fractions reached particle size smaller than $1.0 \mathrm{~mm}$. Chromatographic grade acetone (Merck, Germany) was used in this study. All of the other chemicals were purchased from Chemical Reagent Company of Beijing in analytical grade and all of them were used as received.

\subsection{SCM experiments}

Fig. 1 shows the schematic diagram of the chemical recovery process from waste PCBs using supercritical methanol. The SCM experiments were carried out by using a 200-ml high-pressure reactor made of 316 alloy. The waste PCBs samples were charged into the reactor with methanol of appropriate volume. The solidto-liquid ratios $(\mathrm{S} / \mathrm{L})$ were controlled at $1: 10,1: 20$ and $1: 30(\mathrm{~g} / \mathrm{mL})$, respectively. Air in the reactor was purged by argon gas for $3 \mathrm{~min}$ before the SCM reaction. The pressure inside was monitored by a pressure gauge attached to the reactor. The reactor was heated to selected temperature. Once the reactor had reached the selected temperature, it was held at this temperature for selected residence time. After the SCM reaction, the reactor was cooled naturally to room temperature. SCM experiments were performed with reaction temperature of $300,350,380,400$ and $420^{\circ} \mathrm{C}$, respectively. Reaction times were controlled at 30,60, 90 and $120 \mathrm{~min}$, respectively. The pressure in the reactor was changed during the reaction process and whose value lied on the reaction conditions and the filling rate of the reactor. The reaction conditions of each experiment are described in Table 1 . The reaction conditions applied in each experiment exceeded the critical point of methanol.

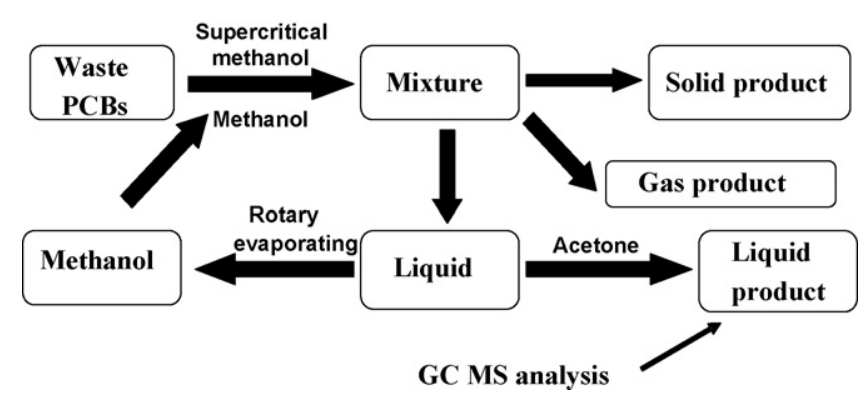

Fig. 1. Schematic diagram of the materials recovery process.

After each SCM reaction, the reactor was cooled to room temperature and the product was taken out of the reactor. The liquid-solid mixture was filtered by a membrane filter with pore size $1.0 \mu \mathrm{m}$. Solid product was rinsed with methanol, then vacuum-dried and weighed. A rotary evaporator was used to recover the solvent methanol, then the oil product was also recovered and weighed. The mass of gas product was calculated by subtracting the mass of the solid product and the oil product from the initial mass of the sample. The conversion efficiency was calculated based on the recovery of oil and gaseous products and defined as follows:

conversion $(\%)=\frac{W_{\mathrm{l}}+W_{\mathrm{g}}}{W_{\mathrm{i}}} \times 100$

where $W_{\mathrm{l}}$ and $W_{\mathrm{g}}$ are the oil and gas mass recovered and $W_{\mathrm{i}}$ the initial mass of waste PCBs sample.

Metals contents in the raw PCBs and in the SCM-treated residues were measured by ICP-OES (OPTIMA 2000, PerkinElmer) after aqua regia digestion [24]. The oils recovered were initially dissolved in $10-\mathrm{ml}$ acetone and diluted 5000 times, then analyzed by GC-MS equipment (Agilent 7890A) with a capillary column (HP-5MS). GC-FID (Shimadzu GC-14B, Column: JW DB-WAX) analysis was used to determine the purity of phenol in the oil products. The $\mathrm{Br}$ concentration was analyzed off-line using a Dionex DX100 ion chromatograph fitted with a Dionex AS4A column.

\subsection{Quality assurance and quality control}

Laboratory quality control procedures include analytical sample duplicates and analyses of method blanks. In every analytical sample of SCM-treated residues, the metal concentration was the average of three measurements for ensuring the precision and accuracy of analysis. Internal reference standard materials (GSB 04-1767-2004, China National Center for Standard Materials) and reagent blanks were also used in the process of analysis to ensure the accuracy.

Table 1

Conditions of SCM experiments $\left(P_{\mathrm{i}}\right.$ : initial pressure; $P_{\mathrm{f}}$ : final pressure)

\begin{tabular}{|c|c|c|c|c|c|}
\hline Experiment & Temperature $\left({ }^{\circ} \mathrm{C}\right)$ & $P_{\mathrm{i}}(\mathrm{MPa})$ & $P_{\mathrm{f}}(\mathrm{MPa})$ & Time (min) & $\mathrm{S} / \mathrm{L}(\mathrm{g} / \mathrm{mL})$ \\
\hline 1 & 300 & 8 & 14 & 60 & $1: 30$ \\
\hline 2 & 350 & 9 & 22 & 60 & $1: 30$ \\
\hline 3 & 380 & 12 & 28 & 60 & $1: 30$ \\
\hline 4 & 400 & 13 & 30 & 60 & $1: 30$ \\
\hline 5 & 420 & 15 & 32 & 60 & $1: 30$ \\
\hline 6 & 380 & 12 & 23 & 30 & $1: 30$ \\
\hline 7 & 380 & 12 & 29 & 90 & $1: 30$ \\
\hline 8 & 380 & 12 & 29 & 120 & $1: 30$ \\
\hline 9 & 380 & 10 & 24 & 60 & $1: 10$ \\
\hline 10 & 380 & 11 & 26 & 60 & $1: 20$ \\
\hline 11 & 350 & 12 & 25 & 60 & $1: 30$ \\
\hline 12 & 350 & 15 & 28 & 60 & $1: 30$ \\
\hline 13 & 350 & 18 & 31 & 60 & $1: 30$ \\
\hline 14 & 350 & 21 & 32 & 60 & $1: 30$ \\
\hline
\end{tabular}




\section{Results and discussion}

\subsection{Compound distribution of oil}

To study the effect of reaction temperature on the compound distribution of oil products, three oils produced from the reaction temperature of 300,350 and $400^{\circ} \mathrm{C}$ for $60 \mathrm{~min}$ were subjected to GC-MS analysis. The results are shown in Fig. 2. The most significant compounds in all the oils were phenol and phenol derivatives. It can be seen from Fig. 2 that when low reaction temperature $\left(300^{\circ} \mathrm{C}\right)$ was performed, the oil was composed of mainly phenol. Methylated derivatives such as $o$-cresol and $p$-cresol also can be found in the oil product of $300^{\circ} \mathrm{C}$, however, the relative abundances (compared with phenol) of these cresols were very low. The relative abundances and category of methylated derivatives increased with the increase of the reaction temperature. The main derivatives included $o$ - and $p$-cresol, 2,6- and 3,5-xylenol, and 2,3,5-trimethylphenol. It is interesting to find that the production of 2,3,5-trimethylphenol under $400^{\circ} \mathrm{C}$ was obvious. However, it is difficult to depolymerize directly to produce 2,3,5-trimethylphenol from resin according to the chemical structure of the resin. Hence, it is believed that some methylation reactions of phenol took place during the SCM process. In fact, reaction between phenol and methanol under hightemperature and high-pressure conditions is inclined to produce methylation products [21].

The chemical recycling of waste PCBs is to decompose the waste polymers into their monomers or some useful chemicals by means of chemical reactions [22]. In general, chemical recycling consists of pyrolysis process, gasification process, depolymerization process by using supercritical fluids and hydrogenolytic degradation. In fact, the chemical recycling of non-metallic fractions from waste PCBs is the process which is the separation of the non-metallic fractions and the metallic fractions from waste PCBs and the upgrading of the products [22]. The refining of the products (gases and oils) is included in the chemical recycling process, however, all the research at present concentrates on the separation and upgrading processes, and the refining process can be done with conventional refining methods in chemical plants [22].

In the present study, according to GC-MS analysis, phenol was the most main component in the oil products, especially in the low and middle reaction temperature ranges (e.g. around $350^{\circ} \mathrm{C}$ ). Hence, phenol in the oil would be a potential chemical product which could be recovered during the refining process with conventional refining methods in chemical plants. To calculate the purity of phenol in oil, GC-FID analysis was conducted. The purity was defined as the phenol mass divided by the mass of oil product. The phenol purity of oils from low, middle, and

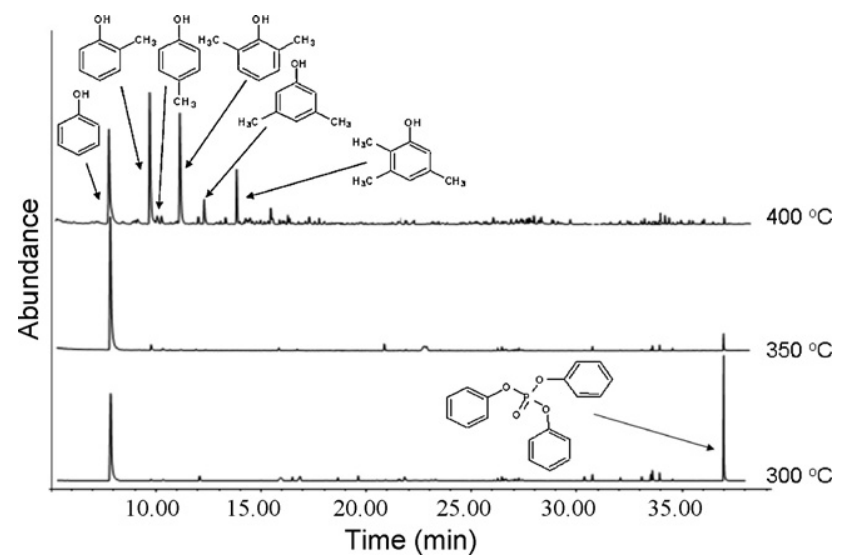

Fig. 2. GC-MS chromatograms of liquid products produced at 300,350 and $400^{\circ} \mathrm{C}$ (reaction time: $60 \mathrm{~min}$; $/ \mathrm{L}: 1: 30, \mathrm{~g} / \mathrm{mL}$ ).
Table 2

Phenol purity of oils (reaction temperature 300,350 , and $400^{\circ} \mathrm{C}$ ).

\begin{tabular}{llll}
\hline Temperature $\left({ }^{\circ} \mathrm{C}\right)$ & 300 & 350 & 400 \\
\hline Purity of phenol $(\%)$ & 34 & 58 & 24 \\
\hline
\end{tabular}

Reaction time: $60 \mathrm{~min}$ S/L: 1:30, g/mL.

high reaction temperatures $\left(300,350\right.$ and $\left.400^{\circ} \mathrm{C}\right)$ is shown in Table 2.

It can be found that with increase in the reaction temperature, the phenol purity of oil was influenced significantly by the temperature. The purity of phenol was only $34 \%$ in the low reaction temperature $\left(300^{\circ} \mathrm{C}\right)$ due to the presence of large amount of phosphated flame retardants, triphenyl phosphate (see the GC-MS chromatograms in Fig. 2). The highest phenol purity (58\%) could be obtained in the middle reaction temperature $\left(350^{\circ} \mathrm{C}\right)$, because the triphenyl phosphate decreased to very low level and little methylated derivatives of phenol were produced. However, a large amount of methylated derivatives of phenol were produced in the high reaction temperature $\left(400^{\circ} \mathrm{C}\right)$ due to the methylation reactions of phenol, and the purity of phenol also decreased to very low level (only 24\%). Accordingly, it is recommended that middle temperature $\left(350^{\circ} \mathrm{C}\right)$ is favorable for phenol recovery. The further recovery process of phenol could be conducted easily in conventional chemical plants [22].

Another major concern over the chemical recycling of waste PCBs is the presence of flame retardants. Brominated and/or phosphated additives are added to circuit boards and circuit board components to reduce the flammability of the boards, these additives are often toxic [25]. In our present study, no brominated compounds can be found in the oils from the GC-MS chromatograms in Fig. 2. One possible reason was that the decomposition and debromination of brominated flame retardants in waste PCBs were complete during the SCM process. If it is true, the decomposed brominated compounds may exist in the gas phase. In fact, it can be easily found that the gas collected after SCM reactions give strong smell of bromide.

Up to now, many methods [26-28] have been proposed for the treatment of $\mathrm{Br}$ existed in the gaseous products derived from the pyrolysis of WEEE. The released $\mathrm{HBr}$ present in the pyrolysis gas could be scrubbed in a wet gas cleaning system. The scrubber needs to operate under acidic conditions. The acids present, $\mathrm{HBr}$ will be quenched in the aqueous solution. Three main process routes, distillation, neutralization, and peroxide are available to convert the acid into usable products [26-28].

In the present study, the gaseous product produced from the SCM process was introduced into an water-cooled aqueous solution system including $3 \mathrm{~g} / \mathrm{L} \mathrm{HBr}$ and $0.5 \mathrm{~mol} / \mathrm{L}$ sodium thiosulfate, which was used to convert $\mathrm{Br}_{2}$ (it is very possible that some $\mathrm{Br}_{2}$ existed in the gas product) into $\mathrm{HBr}$. The final $\mathrm{Br}^{-}$concentration was analyzed off-line using a Dionex DX100 ion chromatograph fitted with a Dionex AS4A column. The final $\mathrm{Br}^{-}$concentration was $13.5 \mathrm{~g} / \mathrm{L}$, which was suitable for the recovery of bromine according to reference [26]. A simple distillation setting in lab scale was used to recover the bromine. A $41 \% \mathrm{HBr}$ solution could be obtained after the distillation process, which can be sent for industry application directly.

On the other hand, the oils contained a significant number of phosphated compounds, the most abundant of which is triphenyl phosphate (triphenyl phosphate). When a low temperature $\left(300^{\circ} \mathrm{C}\right)$ was performed in the recovery process, the relative content of triphenyl phosphate was very high, even higher than phenol in the oil. But the relative abundance of triphenyl phosphate decreased significantly with the increase of reaction temperature, especially at $400^{\circ} \mathrm{C}$. The possible reason was that the decompo- 
Table 3

Content of metals in solid product obtained from the SCM process at different temperatures $(\mathrm{mg} / \mathrm{kg}$ ) (reaction time: $60 \mathrm{~min} ; \mathrm{S} / \mathrm{L}: 1: 30, \mathrm{~g} / \mathrm{mL}$ ).

\begin{tabular}{|c|c|c|c|c|c|}
\hline & \multicolumn{5}{|c|}{ Temperature $\left({ }^{\circ} \mathrm{C}\right)$} \\
\hline & $C_{\mathrm{i}}$ & 300 & 350 & 380 & 420 \\
\hline $\mathrm{Al}$ & 2913 & 3697 & 3895 & 4440 & 6842 \\
\hline As & 483 & 869 & 934 & 1191 & 1368 \\
\hline $\mathrm{Ba}$ & 188 & 282 & 401 & 442 & 569 \\
\hline $\mathrm{Be}$ & 799 & 1196 & 1250 & 1646 & 2250 \\
\hline $\mathrm{Cu}$ & 94,845 & 142,208 & 155,806 & 205,557 & 343,574 \\
\hline $\mathrm{Zn}$ & 7555 & 9231 & 12,841 & 14,976 & 26,715 \\
\hline $\mathrm{Ni}$ & 421 & 556 & 790 & 851 & 1203 \\
\hline Co & 63 & 97 & 104 & 123 & 199 \\
\hline $\mathrm{Fe}$ & 26,500 & 39,797 & 48,709 & 52,215 & 79,717 \\
\hline Mn & 1396 & 2021 & 2348 & 2770 & 4585 \\
\hline $\mathrm{Cr}$ & 167 & 250 & 276 & 388 & 482 \\
\hline $\mathrm{Ti}$ & 649 & 987 & 1012 & 1257 & 2004 \\
\hline $\mathrm{Sr}$ & 114 & 152 & 161 & 269 & 342 \\
\hline $\mathrm{Li}$ & 18 & 23 & 34 & 35 & 57 \\
\hline $\mathrm{Mg}$ & 292 & 425 & 478 & 536 & 837 \\
\hline $\mathrm{Cd}$ & 182 & 250 & 298 & 356 & 577 \\
\hline V & 148 & 202 & 242 & 295 & 378 \\
\hline $\mathrm{Sb}$ & 902 & 1382 & 1527 & 1619 & 2895 \\
\hline Sn & 27,010 & 40,668 & 45,943 & 56,010 & 79,390 \\
\hline $\mathrm{Ga}$ & 114 & 171 & 193 & 232 & 341 \\
\hline $\mathrm{Pb}$ & 21,256 & 31,480 & 38,886 & 44,976 & 63,815 \\
\hline $\mathrm{Ag}$ & 2625 & 3911 & 4350 & 5200 & 7902 \\
\hline $\mathrm{Au}$ & 5 & 7 & 8 & 12 & 17 \\
\hline
\end{tabular}

$C_{\mathrm{i}}$ : initial metal content in waste PCBs.

sition of triphenyl phosphate at high temperature could be easily achieved.

\subsection{Metal distribution of solid products}

After SCM treatment, the color of the solid product changed from gray, the original color of the waste PCBs sample, to brown (300 and $350^{\circ} \mathrm{C}$ ) or black $\left(380,400\right.$ and $\left.420^{\circ} \mathrm{C}\right)$. To analyze the metals present in the solid products, each of the solid product was digested by aqua regia and then determined using an ICP-OES, and the results are presented in Table 3.

Cu was the largest fraction presenting in all of the solid products obtained from different reaction temperature. $\mathrm{Cu}$ content in solid product increased from $9.4 \%$ (the initial Cu content in waste PCBs) to $34 \%$ when the reaction temperature of $420^{\circ} \mathrm{C}$ was used in the $\mathrm{SCM}$ process. Hence the concentrated function of SCM process was obvious over the metals in waste PCBs. High concentrations of Fe, $\mathrm{Sn}, \mathrm{Pb}$ and $\mathrm{Zn}$ also can be found in the solid products obtained from the reactions of different temperatures. In addition, the solid products contained significant concentration of precious metal Ag $(7902 \mathrm{mg} / \mathrm{kg})$, and a lower concentration of Au also can be examined.

\subsection{Effect of reaction temperature on the products}

Fig. 3a shows the effect of reaction temperature on the product conversion efficiency. The conversion efficiency increased with the increase of reaction temperature and a more rapid increase could be obtained above $350^{\circ} \mathrm{C}$, indicating that the depolymerization reaction of resins in waste PCBs took place obviously in this temperature range.

The product distributions of the reactions under different reaction temperature discussed above are presented in Fig. 3b. When the reaction temperature increased from 300 to $380^{\circ} \mathrm{C}$, the increase of the conversion efficiency mainly resulted from the increase of oil. However, the increase of the conversion efficiency mainly resulted from the increase of gas product when the reaction temperature $>400^{\circ} \mathrm{C}$, because it can be seen that the mass of the oil kept a stable level during this temperature range. The increased gas product could be produced by either the direct conversion from the solid residue or the cracking reaction of the oil.

\subsection{Effect of reaction time on the products}

The effect of reaction time on the product conversion efficiency is shown in Fig. 4a. The conversion efficiency increased rapidly with the increase of reaction time. It can be seen that the highest conversion efficiency, $67 \%$, could be attained when reaction time and temperature were $120 \mathrm{~min}$ and $380^{\circ} \mathrm{C}$, respectively. It should be noted that the conversion efficiency was much higher than that of the reaction at $420^{\circ} \mathrm{C}$ for $60 \mathrm{~min}(59 \%)$. It seems that it has significant different effects on the products between the following two reaction conditions: (1) a longer reaction time with lower reaction temperature and (2) a shorter reaction time with higher reaction temperature. In order to further make clear this point, the effect of reaction time on the product distributions was also studied and the results are presented in Fig. $4 \mathrm{~b}$.

It is interesting to find in Figs. $3 \mathrm{~b}$ and $4 \mathrm{~b}$ that the product distributions obtained from the two reaction conditions discussed above were also very different from each other. The gas and oil composition at $380^{\circ} \mathrm{C}$ for $120 \mathrm{~min}$ was $13 \%$ and $54 \%$, respectively. However, the gas and oil composition at $420^{\circ} \mathrm{C}$ for $60 \mathrm{~min}$ was $18 \%$ and $41 \%$, respectively. Accordingly, from the point of view for oils recovery, the reaction condition of longer reaction time with lower temperature would be more favorable.

\subsection{Effect of reaction pressure on the products}

Pressure has an essential effect on the treatment efficiency in supercritical fluid extraction system because the fluid density is directly associated with the pressure. To understand the effect of pressure on the products of SCM reaction, five different initial pres-
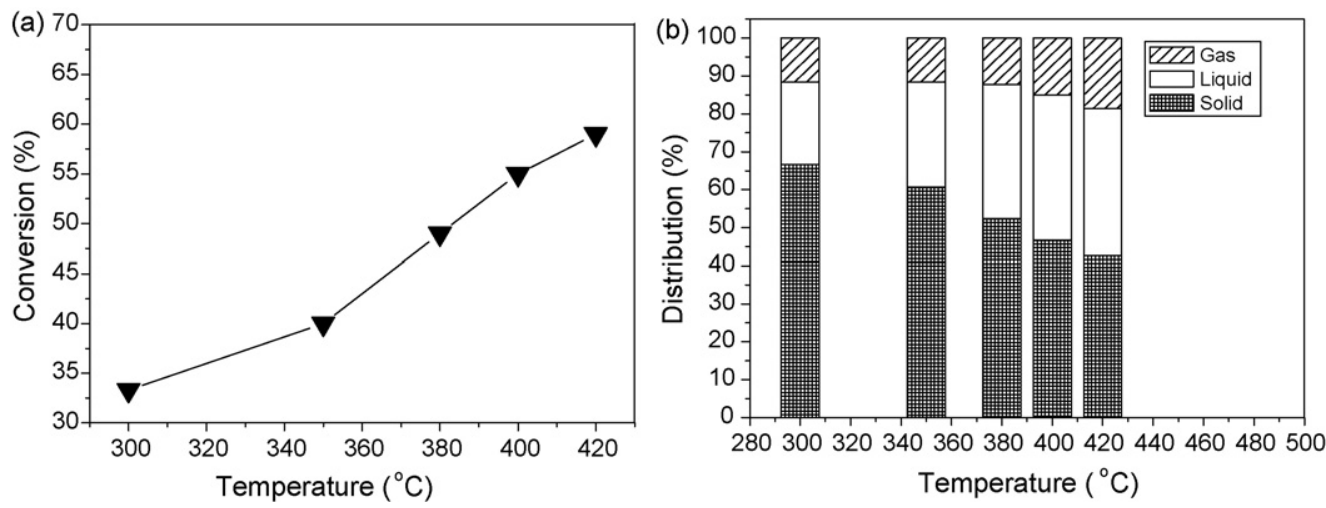

Fig. 3. Effect of reaction temperature on the product conversion rate and distribution (reaction time: $60 \mathrm{~min} ; \mathrm{S} / \mathrm{L}: 1: 30, \mathrm{~g} / \mathrm{mL}$ ). 

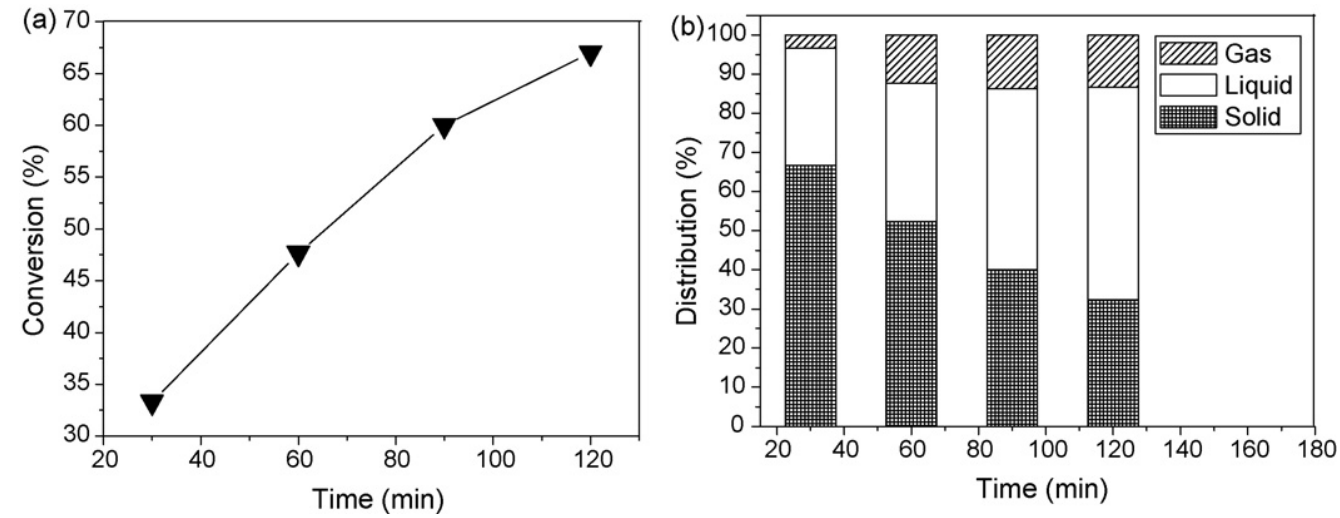

Fig. 4. Effect of the reaction time on the product conversion rate and distribution (reaction temperature: $380^{\circ} \mathrm{C} ; \mathrm{S} / \mathrm{L}: 1: 30, \mathrm{~g} / \mathrm{mL}$ ).
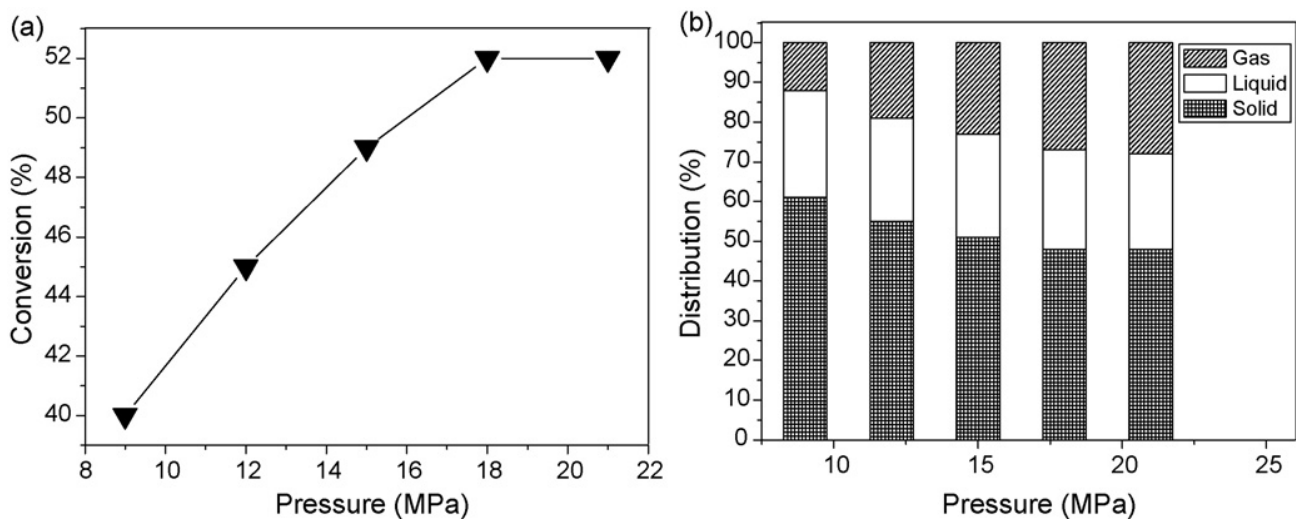

Fig. 5. Effect of the reaction pressure on the product conversion rate and distribution (reaction temperature: $350{ }^{\circ} \mathrm{C} ; \mathrm{S} / \mathrm{L}: 1: 30, \mathrm{~g} / \mathrm{mL}$ ).

sures $(9,12,15,18$, and $21 \mathrm{MPa})$ were applied in the SCM process. The results about the effect of reaction pressure on the product conversion efficiency and distribution are shown in Fig. 5a and b, respectively.

The conversion efficiency increased with the increase of reaction pressure and reached a steady level when the initial pressure was higher than $18 \mathrm{MPa}$ (Fig. 5a). It can be found in Fig. 5b that the solid product decreased evidently with the increase of initial pressure, however, the gas product increased significantly. It is interested to find that the change of the oil was minor under different initial reaction pressures. It seems that the increase of the gas product mainly resulted from the decrease of solid product. The possible reason is that the direct gasification of the polymer materials in the waste PCBs became more effectively when the reaction pressure increased. According to our previous studies [29,30], supercritical fluid is strong enough to destroy the solid particles, this treatment process could produce some porous structure in the solid waste particle. As a result, SCM molecules probably can diffuse into the waste PCBs particle through the porous structure and eventually create big holes in the particle. The holes in the particle are supposed to be positive for facilitating the diffusing of gas offspring produced inside the waste PCBs during the SCM process.

\subsection{Effect of $S / L$ ratio on the products}

Fig. $6 a$ and $b$ shows the effect of S/L ratio on the product conversion efficiency and distribution, respectively.

An increase trend of the conversion can be observed in Fig. 6a when the $\mathrm{S} / \mathrm{L}$ ratio changed from $1: 2$ to $1: 20(\mathrm{~g} / \mathrm{mL})$. The increase of the conversion efficiency could be attributed to the simultane-
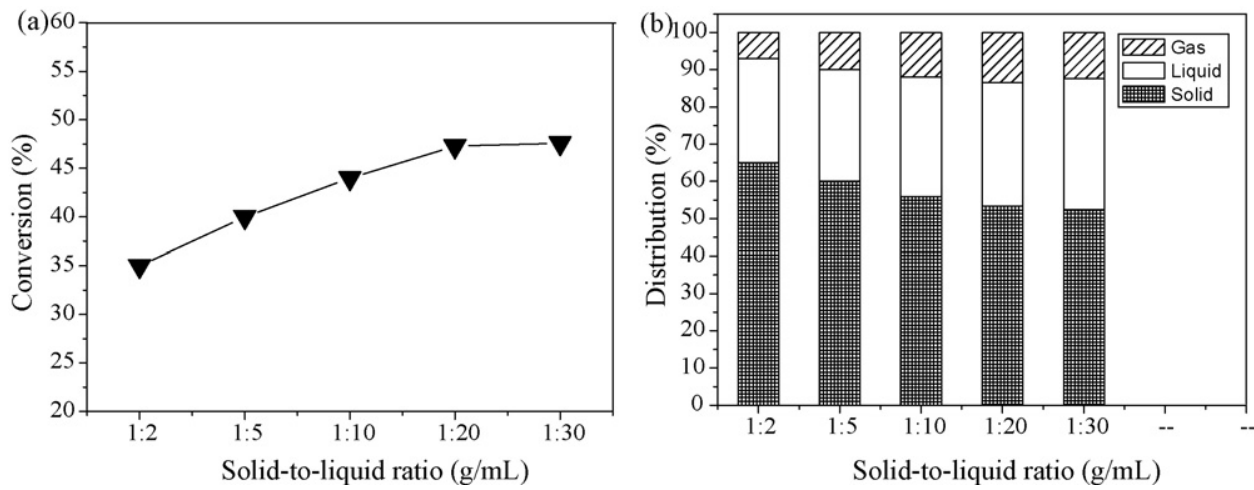

Fig. 6. Effect of the $\mathrm{S} / \mathrm{L}$ ratio on the product conversion rate and distribution (reaction temperature: $380^{\circ} \mathrm{C}$; reaction time: $60 \mathrm{~min}$ ). 
Table 4

Quantitative comparison of present study with other methods on waste PCBs recycle.

\begin{tabular}{|c|c|c|c|c|c|c|c|}
\hline Method & Temperature $\left({ }^{\circ} \mathrm{C}\right)$ & Time (min) & Solid yield (\%) & Oil yield (\%) & Gas yield (\%) & Purity of phenol (\%) & Source \\
\hline Pyrolysis under $\mathrm{N}_{2}$ & 800 & 135 & 70.7 & 21 & 4.2 & 25.23 & Williams and Hall [1] \\
\hline Pyrolysis under $\mathrm{N}_{2}$ & 500 & 30 & 76.5 & 16.2 & 7.3 & 36.1 & Marco et al. [3] \\
\hline Pyrolysis & 300 & 30 & 84.9 & 5.2 & 9.9 & - & Guan \\
\hline under & 400 & 30 & 80.9 & 6.9 & 13.6 & - & et \\
\hline \multirow[t]{3}{*}{$\mathrm{N}_{2}$} & 500 & 30 & 78 & 9.1 & 12.9 & - & al. \\
\hline & 600 & 30 & 77.7 & 9.1 & 13.2 & - & {$[10]$} \\
\hline & 700 & 30 & 77.2 & 8.9 & 13.9 & - & \\
\hline Vacuum pyrolysis & 550 & 120 & 74.7 & 15 & 10.3 & 37.99 & Long et al. [32] \\
\hline Vacuum pyrolysis & 600 & 30 & 69.5 & 27.8 & 2.7 & - & Zhou and Qiu [33] \\
\hline SCM & 380 & 30 & 66 & 30 & 4 & 55 & This work \\
\hline
\end{tabular}

ous increase of the gas and oil yield (see Fig. 6b). At supercritical conditions, supercritical fluid has a high solubility for organics, and organic compounds and supercritical fluid form a single and homogeneous phase, which allows reaction to proceed rapidly by an elimination of the potential interface mass transport limitations [31]. It is possible that the forming of the homogeneous phase reaction system of supercritical methanol and polymer matters in waste PCBs was influenced by the S/L ratio. The increase of the methanol dosage may be more favorable for the forming of the homogeneous phase system and results in the increase of conversion efficiency. However, when further increasing the methanol dosage after $\mathrm{S} / \mathrm{L}$ ratio $1: 20(\mathrm{~g} / \mathrm{mL})$, the change of the conversion efficiency and product distribution was insignificant. The possible reason is that the homogeneous phase system of methanol and polymer was saturated when the $\mathrm{S} / \mathrm{L}$ ratio reached $1: 20(\mathrm{~g} / \mathrm{mL})$.

\subsection{Quantitative comparison with current methods}

Quantitative comparative data with current treatment methods of waste PCBs have been presented in Table 4. Treatment methods discussed here mainly include conventional pyrolysis and the new SCM pyrolysis (this work). Conventional pyrolysis under $\mathrm{N}_{2}$ atmosphere, vacuum pyrolysis, and SCM treatment are compared in Table 4. Quantitative comparative data include reaction condition (temperature and time), yield (solid, oil, and gas), and purity of phenol in oil. It can be found in Table 4 that when conventional pyrolysis was applied, the conversion (oil and gas yield) increased with the increase of reaction temperature and time. The highest conversion can be obtained under $800^{\circ} \mathrm{C}$ and $135 \mathrm{~min}$ [1]. The conversion could be enhanced using vacuum pyrolysis [32,33]. For example, the oil yield could increase to $27.8 \%$ when $600^{\circ} \mathrm{C}$ and $30 \mathrm{~min}$ were applied in the vacuum pyrolysis.

In the present study, SCM was used for the pyrolysis of waste PCBs. The differences of the reaction condition and product yield between the conventional pyrolysis, vacuum pyrolysis and SCM could be found in Table 4 . The superiority of the SCM process could be demonstrated as follows.

Firstly, the temperature applied in SCM $\left(<400^{\circ} \mathrm{C}\right)$ was much lower than the conventional pyrolysis and vacuum pyrolysis, so the energy consumption could be reduced.

Secondly, 30\% oil yield could be obtained using SCM pyrolysis, which was much higher than the conventional and vacuum pyrolysis. Also it is interested to find that the gas yield was relative low when compared with that of conventional and vacuum pyrolysis. However, the gas yield increased significantly with the increase of SCM reaction time (see Fig. 4).

Thirdly, the purity of phenol (the most significant product in oils) we hope to recover improved significantly when SCM process was applied. A 55\% purity phenol could be obtained under $380^{\circ} \mathrm{C}$ and $30 \mathrm{~min}$ reaction. And the recovery of phenol could be conducted easily by conventional refining process in chemical plants.

\section{Conclusions}

(1) SCM treatment is efficient and benign for the materials recovery from waste PCBs. The oils obtained from waste PCBs after SCM treatment mainly included phenol and phenol derivatives. Relative abundances and category of methylated derivatives increased with the increase of the reaction temperature. When the reaction temperature of the SCM process was controlled at $350{ }^{\circ} \mathrm{C}$, the oil containing phenol with $58 \%$ purity could be obtained, which was much higher than that produced by other conventional pyrolysis process. The further recovery of phenol could be conducted easily by conventional refining process in chemical plants. The oils contained a significant number of phosphated fire retardants, triphenyl phosphate under low temperature treatment. However, no brominated compounds can be found in the oils due to the complete decomposition and debromination during the SCM process. Large amount of inorganic $\mathrm{Br}$ existed in the gaseous products, which could be recovered effectively by simple distillation process. A $41 \% \mathrm{HBr}$ solution could be obtained after the distillation, which can be sent for industry application directly.

(2) Product conversion efficiency and distribution were affected significantly by reaction temperature, pressure, time, and S/L ratio. A longer reaction time with lower temperature was more favorable for obtaining a higher yield of oils when compared with the reaction conditions of a shorter time with higher temperature.

(3) Metallic elements in waste PCBs were concentrated effectively after SCM treatment, and the content of metals was up to $62 \%$ under optimum conditions. High concentrations of $\mathrm{Cu}(34 \%), \mathrm{Fe}$ (7.9\%), Sn (7.9\%), $\mathrm{Pb}(6.3 \%)$ and $\mathrm{Zn}(2.6 \%)$ were found in most of the solid products, which were valuable for subjecting to metallurgy process.

\section{Acknowledgements}

This research was financially supported, in part, by the National Key Technology R\&D Program (2008BAC32B03) and the National Basic Research Program (2007CB407303) of China.

\section{References}

[1] W.J.Hall, P.T. Williams, Separation and recovery of materials from scrap printed circuit boards, Resour. Conserv. Recycl. 51 (3) (2007) 691-709.

[2] J. Li, H.Z. Lu, J. Guo, Z.M. Xu, Y.H. Zhou, Recycle technology for recovering resources and products from waste printed circuit boards, Environ. Sci. Technol. 41 (6) (2007) 1995-2000.

[3] I. Marco, B.M. Caballero, M.J. Chomon, M.F. Laresgoiti, A. Torres, G. Fernandez, S. Arnaiz, Pyrolysis of electrical and electronic wastes, J. Anal. Appl. Pyrol. 82 (2008) 179-183.

[4] M. Schlummer, L. Gruber, A. Maurer, W. Gerd, R. Eldik, Characterisation of polymer fractions from waste electrical and electronic equipment (WEEE) and implications for waste management, Chemosphere 67 (2007) 1866-1876. 
[5] F. Sasse, G. Emig, Chemical recycling of polymer materials, Chem. Eng. Technol 21 (1998) 777-789.

[6] G. Grause, M. Furusawa, A. Okuwaki, T. Yoshioka, Pyrolysis of tetrabromobisphenol-A containing paper laminated printed circuit boards, Chemosphere 71 (2008) 872-878

[7] F. Barontini, K. Marsanich, L. Petarca, V. Cozzani, Thermal degradation and decomposition products of electronic boards containing BFRs, Ind. Eng. Chem. Res. 44 (2005) 4186-4199.

[8] F. Barontini, V. Cozzani, Formation of hydrogen bromide and organobrominated compounds in the thermal degradation of electronic boards, J. Anal. Appl. Pyrol. 77 (2006) 41-55.

[9] Y.C. Lai, W.-J. Lee, H.-W. Li, L.-C. Wang, G.-P. Chang-Chien, Inhibition of polybrominated dibenzo-p-dioxin and dibenzofuran formation from the pyrolysis of printed circuit boards, Environ. Sci. Technol. 41 (3) (2007) 957-962.

[10] J. Guan, Y.-S. Li, M.-Xi. Lu, Product characterization of waste printed circuit board by pyrolysis, J. Anal. Appl. Pyrol. 83 (2008) 185-189.

[11] Y. Suzuki, H. Tagaya, T. Asou, J. Kadokawa, K. Chiba, Decomposition of prepolymers and molding materials of phenol resin in subcritical and supercritical water under an Ar atmosphere, Ind. Eng. Chem. Res. 38 (1999) 1391-1395.

[12] O. Tavakoli, H. Yoshida, Effective recovery of harmful metal ions from squid wastes using subcritical and supercritical water treatments, Environ. Sci. Technol. 39 (2005) 2357-2363.

[13] R.E.N. Castro, G.J. Vidotti, A.F. Rubira, E.C. Muniz, Depolymerization of poly(ethylene terephthalate) wastes using ethanol and ethanol/water in supercritical conditions, J. Appl. Polym. Sci. 101 (2006) 2009-2016.

[14] M. Genta, T. Iwaya, M. Sasaki, M. Goto, Supercritical methanol for polyethylene terephthalate depolymerization: observation using simulator, Waste Manag. 27 (2007) 1167-1177.

[15] R. Pinero-Hernanz, J. Garcia-Serna, C. Dodds, J. Hyde, M. Poliakoff, M.J. Cocero, S. Kingman, S. Pickering, E. Lester, Chemical recycling of carbon fibre composites using alcohols under subcritical and supercritical conditions, J. Supercrit. Fluids 46 (2008) 83-92.

[16] M. Goto, Chemical recycling of plastics using sub- and supercritical fluids, J. Supercrit. Fluids 47 (2009) 500-507.

[17] F.-R. Xiu, F.-S. Zhang, Recovery of copper and lead from waste printed circuit boards by supercritical water oxidation combined with electrokinetic process, J. Hazard. Mater. 165 (1-3) (2009) 1002-1007.

[18] F.-R. Xiu, F.-S. Zhang, Electrokinetic recovery of Cd, Cr, As, Ni, Zn and $\mathrm{Mn}$ from waste printed circuit boards: effect of assisting agents, J. Hazard. Mater. 170 (1) (2009) 191-196.
[19] M. Goto, M. Kitamura, T. Hirose, K. Shibata, Depolymerization of printed circuit board in near-critical water, in: Hydrothermal Reactions and Techniques, World Scientific, New Jersey, 2003, 201-208.

[20] H. Tagaya, Y. Shibasaki, C.K.J. Kadokawa, B. Hatano, Decomposition reactions of epoxy resin and polyetheretherketone resin in sub- and supercritical water, $\mathrm{J}$ Mater. Cycles Waste Manag. 6 (2004) 1-5.

[21] J. Ozaki, S.K.I. Djaja, A. Oya, Chemical recycling of phenol resin by supercritical methanol, Ind. Eng. Chem. Res. 39 (2000) 245-249.

[22] J. Guo, Jie. Guo, Z. Xu, Recycling of non-metallic fractions from waste printed circuit boards: a review, J. Hazard. Mater. 168 (2009) 567-590.

[23] H. Lee, J.H. Jeong, H.-K. Cho, C.M. Koo, S.M. Hong, H. Kim, Y.-W. Lee, A kinetic study of the decross-linking of cross-linked polyethylene in supercritical methanol, Polym. Degrad. Stab. 93 (2008) 2084-2088.

24] T. Oishi, K. Koyama, S. Alam, Recovery of high purity copper cathode from printed circuit boards using ammoniacal sulfate or chloride solutions, Hydrometallurgy 89 (2007) 82-88.

[25] A. Tohka, R. Zevenhoven, Brominated flame retardants-a nuisance in thermal waste processing? in: TMS Extraction and Processing Division Meeting on Recycling and Waste Treatment in Mineral and Metal Processing: Technical and Economic Aspects, Lulea, Sweden, June 16-20, 2002.

[26] M. Bientinesi, L. Petarca, Comparative environmental analysis of waste brominated plastic thermal treatments Waste Manag. 29 (2009) 1095-1102.

[27] J. Velhow, B. Bergfeldt, H. Hunsinger, K. Jay, Recycling of Bromine from Plastics Containing Brominated Flame Retardants, Association of Plastic Manufactures in Europe (APME). http://www.apme.org.

[28] L. Tange, D. Drohmann, Waste management concept for WEEE plastic containing brominated flam retardants, including bromine recycling and energy recovery, in: Challenges for Flame Retardants in Polymer Systems, 2003, Brussels, p. 12

[29] F.-S. Zhang, H. Itoh, A novel process utilizing subcritical water and nitrilotriacetic acid to extract hazardous elements from MSW incinerator fly ash, Sci. Total Environ. 369 (2006) 273-279.

[30] D. Bo, F.-S. Zhang, L. Zhao, Influence of supercritical water treatment on heavy metals in medical waste incinerator fly ash, J. Hazard. Mater. 170 (2009) 66-71.

[31] Y.-C. Chien, H.P. Wang, K.-S. Lin, Y.W. Yang Oxidation of printed circuit board wastes in supercritical water, Water Res. 34 (17) (2000) 4279-4283.

[32] L. Long, S. Sun, S. Zhong, W. Dai, J. Liu, W. Song, Using vacuum pyrolysis and mechanical processing for recycling waste printed circuit boards, J. Hazard. Mater. (2008), doi:10.1016/j.jhazmat.2009.12.078.

[33] Y. Zhou, K. Qiu, A new technology for recycling materials from waste printed circuit boards, J. Hazard. Mater. 175 (2010) 823-828. 